\title{
Banking on blockchain: how banks and financial institutions can implement the blockchain technology
}

\author{
E. Tikhomirova \\ Department of banks, financial markets \\ and insurance, St. Petersburg State \\ University of Economics (UNECON) \\ Saint Petersburg, Russia \\ tihom06@mail.ru
}

\author{
A. Soia \\ Department of banks, financial markets \\ and insurance, St. Petersburg State \\ University of Economics (UNECON) \\ Saint Petersburg, Russia \\ artem_soya@mail.ru
}

\begin{abstract}
Blockchain is used in a variety of areas. This technology is relatively young, but it has already begun to pay important role in various sectors of the economy. Today, many people talk about prospects and properties of blockchain technology, about what it is capable of and what risks and opportunities it opens. At the same time, very often the opportunities to use blockchain in the banking sector are not covered. Therefore, it is necessary to study all the ways of using blocking technology in the bank. In the article the authors analyze the main areas of application of blocking technology in banks and other financial institutions.
\end{abstract}

Keywords - blockchain, payment system, letter of credit, virtual banking, ICO, scoring, analysis of big data, swift, Ethereum, Ripple.

\section{INTRODUCTION}

It is worth noting that originally the technology of blockchain appeared in conjunction with cryptocurrency, and for the certain period of time it was associated with it. However, recently technology of blockchain has gradually turned into a separate instrument and mechanism for carrying out various operations, which will be discussed later.

The scope of the blockchain technology is very extensive:

Document workflow; Audit; Analysis of big data; Complex scenarios; Operations on stock exchange; Clearing; Crowdfunding (in ICO format); Scoring, etc.

The authors will consider some of these applications in more detail

\section{MAIN PART}

The first that has to be mentioned is the interaction with databases. Such a document workflow will facilitate the relationships between banks and customers through the creation of complete customer identification system, as a result, the time for customer identification will be reduced to several seconds; simplification of the process of searching, storing and analyzing information by banks, public institutions and shareholders, making financial reports more difficult to alter and forge, etc. It will be, for example, much easier to establish the origin of money, leading to transparency. [1-2] Moreover, a bank will not be able to have off-balance-sheet customers or conduct questionable transactions, as this will immediately be reflected in the network.

The units of such a system are the nodes. Nodes in such a system are responsible for initiating a record in a data block. In this case, all the nodes form a public notary to confirm all records. The scheme of such functioning on the blockchain system is shown at Figure 2.

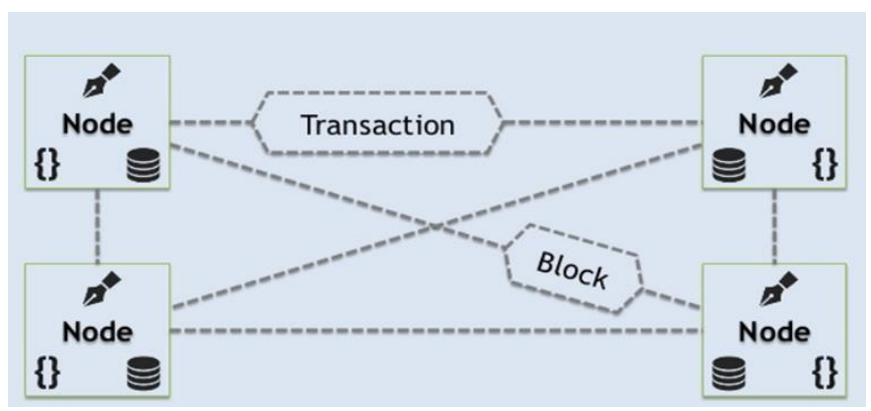

Fig. 1. Schema of interaction with databases on the Blockchain system

Another way to use block technology is to record all transactions in a common transaction log. [3] In that case the reporting will be formed and confirmed with all the operations of a particular company. There will be companies in the network with various connections between them. After each operation, the node of the company will be recorded to the system and the rest of the network participants will have to confirm this record. That is, the notary will collectively be involved in the case, able to receive any operation and transaction. This will lead to two important consequences: mitigate trade frauds and increase external control. [4] Moreover, the importance of auditing in this scenario may decrease as operations are confirmed by the market. Automatic control is more complex and more effective than manual.

The second notable application of blocking technology is in the scoring of customers. This will happen as the system collects information through big data and learns to draw conclusions about a credit limits for a client. It should be noted that scoring can include not only conventional analysis of the financial indicators, but also psycho-scoring. This becomes possible due to the analysis of big data, from the dates on which a salary is paid, to the analysis of behavioral characteristics of the potential borrower. Moreover, neural networks will help improve the system and adapt to each client, and as a consequence, to offer highly customized financial products. The system will be continuously trained, it will study and predict the client's behavior and its needs in the near future. [5] This will allow banks to create individual offers for each client. For example, it can foresee cash flow gaps, etc. Such a development will lead to a reduction in the number of underwriters, an increase in scoring accuracy up to $85 \%$ [6], and compiling forecasts for them. 
The third way to apply blockchain technology is letters of credit, instead of which banks will use smart contracts. [7-8] The letter of credit is one of the ways to reduce risks in international trade, but it has a number of shortcomings. Blockchain is able to make this tool more simple, efficient and reliable.

The best way to describe smart contracts is to compare this technology to a vending machine. Usually you should contact a layer or a notary, pay them and wait until you receive the document processed by them. Using smart contracts, you simply throw bitcoin into the vending machine (that is, the distributed blockchain ledger), as well as your task for execution and confirmation, and get result that is verified and performed by the network. Moreover, smart contracts not only define rules and penalties for the agreement in the same way as a traditional contract, but also automatically executes them. To put it in a nutshell, this is the most transparent version of clearing, with all participants in one common blockchain space.

The current practice of working on letters of credit involves several financial institutions, sending a large number of documents, which is costly and time consuming. [10-13] Banks can only superficially check the documents, and the parties have no control over various stages of the transaction. With the help of blockchain technology, sending and checking documents becomes almost instantaneous, all the parties involved can actively participate in the process, and automatic payments are now possible. Due to the fact that all stages of the process occur online, the total time of transaction is more than halved. Most large banks are currently assessing the feasibility of using blockchain for this kind of operations.

Another way to use blockchain technology is to use them as payment systems.

"Bank Barclays held the world's first real trade deal on blockchain. The deal between Irish dairy producer Ornua and the Seychelles trading company took less than 4 hours, while traditionally this process took up to 10 days"[4].

In Russia the first such transaction was executed in December 2016 when the company S7 with the help of Alfa-
Bank carried out settlements with one of its counterparties. Opening and execution of the letter of credit took place in the Ethereum blockchain system.

As it known, now SWIFT is used for conducting international bank transfers, the disadvantages of which are costs when making a one-time contribution and expensive maintenance, acquisition of company shares, the need for intermediaries. There is also a possibility of certain political pressure, in the form of threat of disconnection of some or all banks of a certain country from a system. This has happened with the Crimea and the DPRK.

Firstly, Blockchain is able to mitigate these disadvantages, and secondly, it can be used as its alternative, in case of disconnection of a country from SWIFT.

Ways of improving this system of transferring money through intermediates between the sending banks and the receiving banks is proposed by companies such as Ripple. "It is a decentralized payment technology that makes possible to make free and instant payments anywhere in the world" [9]. Ripple does not supplant conventional payment channels, such as SWIFT, but rather connects them. Although Ripple system has its own XRP cryptocurrency, transactions can be executed in any currency. While traditional crypto-currencies are designed to be used by ordinary users and to become alternative means of payment, Ripple, on the contrary, actively integrates into the banking industry. Its main customers are large banks and financial institutions. The advantage of this platform is also the fact that it has complete anonymity, which is an important point for banks. Ripple does not require mining, and therefore does not consume such a huge amount of electricity, which is necessary for securing Bitcoin network. Instead, Ripple has initially released a fixed amount of 100 billion XRP. When Ripple process a transaction, $0.00001 \mathrm{XRP}$ is written off, i.e. they are destroyed. This is necessary to counteract spam transactions. Thus, the total amount of the XRP currency will gradually decrease, and its price will rise. The system will have the following structure.

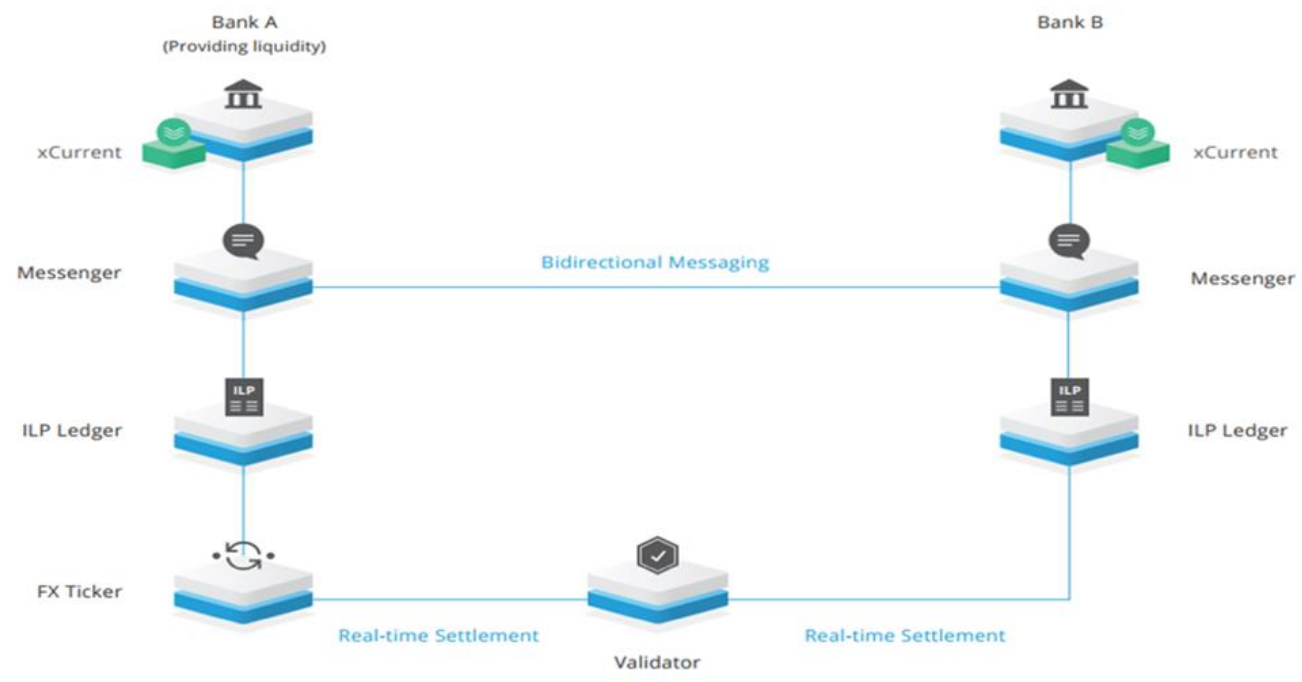

Fig. 2. Structure of Ripple payment system 
Messenger is a component of bidirectional communication through xCurrent (xCurrent is a Ripple technology that allows banks to send messages and process transactions with increased speed, transparency and efficiency with RippleNet).

Validator is a component of the system that cryptographically confirms the success or failure of a payment, when a sender bank sends a payment. It coordinates the flow of funds between the parties, eliminating all settlement risks and minimizing delays.

ILP Ledger is based on a smart contract, distributed accounting ledger for each bank.

FX Ticker is a component of $x$ Current, which facilitates the exchange between ILP Ledgers, allowing liquidity providers to publish exchange rates. This component quotes an exchange rate for any pairs of ledgers with which it is configured to work.

The system supports several currencies, that is, there is no binding to the dollar, euro or any other currency. It is possible to make transactions in any currencies. Any currency is converted into any currency at the current exchange rate in seconds. At the same time, there are Validators on each section of the path automated transaction confirmation mechanisms which guarantee consistency.

The last option, which authors wanted to cover is the investment activity of banks. It is also possible to consider the use of blockage as from the side of the bank. Then the block will be a kind of trading algorithm or it can be regarded as a mechanism for the interaction of bidders on the stock exchange. This is much more complicated and more important. In this case, the system itself will evaluate and find the right counterparty. The system itself will be able to carry out a complex clearing/ So that making mistakes will be practically impossible. All transactions of bidders will be constantly confirmed and monitored. The share register will also be contained in the block, which will facilitate the interaction. It is also interesting to use blocking as a currency converter on the exchange. That is, you can enter the market with any currency.

Billions of dollars are being invested in blockchain, and some of the smartest people on the planet are engaged in understanding how this technology can reinvent organizations and industries. [14] The potential impact of blockchain is driving businesses to rethink existing business models, re-examine opportunities previously thought nonviable, and explore a new frontier of opportunity that can impact the bottom line and benefit society. [15]

Now a new intellectual global economy is built on an innovative digital platform of trust. Borders are no longer boundaries and opportunities are endless. Organizations that have the ability to reinvent themselves, that exceed costs to unlock new business opportunities in a commercially viable way at speed will thrive in the digital age. Financial services companies are already well on their way to adoption of the block.

For this reason, the authors consider it necessary to study the potential impact of this technology on all business processes, not only in the financial sector, but in the entire economy. Since this can become a stepping stone for the creation of a smart society of the future.

In conclusion, it is worth noting that the technology of blockchain has clear potential for banks and all economy system. [16] The authors have come to the conclusion that blockchain technology can lead to significant reductions in the costs and, in fact, the creation of alternative economy. Such an economy, where a big role will be given to digital technologies. Such an economy will function with fewer intermediaries in all its areas, including financial ones. However, the problem is that blockchain technology has been created to make financial intermediaries obsolete. So, the main question is how to combine the experience of financial institutions and the innovation of blockchain technology.

\section{REFERENCES}

[1] B. Imran, "Mastering Blockchain", Packt, 2017. — p. 531.

[2] C. Barski., C. Wilmer "Bitcoin for the Befuddled" No Starch Press, 2014, pp. $120-125$.

[3] C. Marhulia .Messages and materials of the news agency RBC. Retrieved February 9, 2018, from rbc.ru: https://www.rbc.ru/finances/08/09/2016/57d189e79a7947ab7bf496d2

[4] Dr. H. Garrick \& R. Michel (2017). "Global Cryptocurrency Benchmarking Study". London: University of Cambridge.

[5] E. Alpaydin. "Machine Learning: The New AI", The MIT Press Cambridge, Massachusetts London, England, 2016, pp. 79-82.

[6] F. Ekaterina. "Blockchain - the experience of Sberbank of Russia", Retrieved February 2, 2018, from smileexpo.ru: https://www.smileexpo.ru/public/upload/showsEvent/ispolzovanie_blokc heyn_tehnologiy_v_bankovskoy_sisteme_rossi_14794813894542_file.p df. S1. 2-4.

[7] M. Andreas "Mastering Bitcoin: Unlocking Digital Cryptocurrencies", O’Reilly. Copyright 2014, pp. 250-258.

[8] S. Melanie. "Blockchain Blueprint for a New Economy", O'Reilly Media, 2015 pp.15-17.

[9] S. Chris. "ValueWeb. How Fintech Firms are Using Bitcoin Blockchain and Mobile Technologies to Create the Internet of Value", Singapore, Marshall Cavendish business publisher, 2017, pp. 220-245.

[10] T. Don, T. Alex. "Blockchain Revolution: How the Technology Behind Bitcoin is Changing Money, Business, and the World”. New York : Portfolio / Penguin., 2016, p. 320.

[11] Bataev A.V. \& Rodionov D.G., "Cloud computing: Evaluation use under the crisis in Russia". 2018 7th International Conference on Industrial Technology and Management (ICITM), Oxford, 2018, pp. 224-228. doi 10.1109/ICITM.2018.8333951.

[12] G. Bagiev, O. Pogrebova, E. Konnikov. "Marketing platform of organization of system-spatial complex "PSE" (Production - Science Education)". Proceedings of the 2017 International Conference "Quality Management, Transport and Information Security, Information Technologies", pages 466-470, 2017.

[13] Kozlovsky, V., Klochkov, Y., Ostapenko, M., Ushanova, N., Antipov, D. (2016). Conformity assessment of car quality databases exemplified on the case of the Russian car manufacturer 'Auto VAZ'. 2016 5th International Conference on Reliability, Infocom Technologies and Optimization, ICRITO 2016: Trends and Future Directions, 7784925, pp. 57-60. DOI: 10.1109/ICRITO.2016.7784925

[14] Borremans A.D., Zaychenko I.M., Iliashenko, O.Yu. Digital economy. IT strategy of the company development. MATEC Web of ConferencesVolume 170, 13 June 2018. International Science Conference on Business Technologies for Sustainable Urban Development, SPbWOSCE 2017. Paper number 010342017

[15] Vasilievich, B.A., Vladimirovna, V.Y. (2015). Methods for the assessment of the economic potential of an industrial enterprise: Analysis and characterization. Proceedings of the 25th International Business Information Management Association Conference - Innovation Vision 2020: From Regional Development Sustainability to Global Economic Growth, IBIMA 2015, pp. 1294-1302 